\title{
Mycosis Fungoides in Relation to Environmental and Occupational Exposures: A Case-Control Study in the Tunisian Center
}

\author{
I. Kacem 1*, M. Hafsia1, L. Bousoffara'2, N. Ghariani Fetoui'2, O. El Maalel1', W. Boughattas',

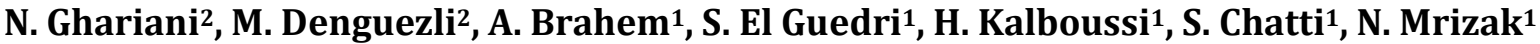 \\ ${ }^{1}$ Occupational Medicine Department, Teaching Hospital Farhat Hached Sousse, Tunisia \\ ${ }^{2}$ Dermatology Department, Teaching Hospital Farhat Hached Sousse, Tunisia \\ Email: *kacem.imane@live.fr
}

How to cite this paper: Kacem, I., Hafsia, M., Bousoffara, L., Fetoui, N.G., El Maalel, O., Boughattas, W., Ghariani, N., Denguezli, M., Brahem, A., El Guedri, S., Kalboussi, H., Chatti, S. and Mrizak, N. (2018) Mycosis Fungoides in Relation to Environmental and Occupational Exposures: A Case-Control Study in the Tunisian Center. International Journal of Clinical Medicine, 9, 528-539. https://doi.org/10.4236/ijcm.2018.96046

Received: May 17, 2018

Accepted: June 12, 2018

Published: June 15, 2018

Copyright (c) 2018 by authors and Scientific Research Publishing Inc. This work is licensed under the Creative Commons Attribution International License (CC BY 4.0).

http://creativecommons.org/licenses/by/4.0/

\section{(c) (i) Open Access}

\begin{abstract}
Introduction: The mycosis fungoides (MF) is the most common cutaneous T-cell lymphomas representing about $50 \%$ of all cutaneous lymphomas. Its pathogenesis remains poorly understood. Thus, its rising incidence rates call for an explanation. Several environmental and occupational factors have been implicated in the pathogenesis of this disease. Objective: To determine the potential occupational factors correlated in the occurrence of MF. Methods: Case-control study was carried out at the teaching Hospital Farhat Hached of Sousse (Tunisia) to investigate associations of MF and occupational risk factors. A questionnaire on lifetime job history was administered to 24 cases and controls. Cases were patients with MF and whose diagnosis was suspected by a dermatologist and confirmed by pathological examination. Controls were patients consulting in the occupational medicine department and matched to cases by age and gender. Bivariate analysis was used to calculate odds ratios (OR) and 95\% confidence intervals (CI). Results: The average age of onset of the disease was $55.41 \pm 17.4$ years with a sex ratio of 2.42 . We found an increased risk of MF associated with tobacco consumption higher than 40 Pack-year $(\mathrm{OR}=6.6 ; 95 \% \mathrm{CI}=1.22$ to 35.4$)$, exercise in the textile sector (OR = 9.4; $\mathrm{CI}=1.06$ to 84.3$)$ and exposure to diesel exhaust $(\mathrm{OR}=9.47 ; 95 \% \mathrm{CI}=$ 1.06 to 84.3). Conclusion: Occupational factors could play a role in the pathogenesis of MF. Regarding our study, smoking, working in the textile industry and exposure to diesel exhaust appear to be involved in the pathogenesis of MF. Further investigation is needed to confirm these findings.
\end{abstract}

\section{Keywords}

Mycosis Fungoides, Occupational Factors, Tobacco, Textile Sector, Diesel 
Exhaust

\section{Introduction}

Nowadays, man is exposed to more than 60,000 chemical substances because of the industrial activity incessant growth [1]. Occupational exposure to some of these substances was incriminated in the genesis of some cancers in an important population of employees [1].

Indeed, cancers are serious and multifactorial illnesses whose occupational origin represents a significant part [2].

The primitive cutaneous lymphomas represent a heterogeneous group of $\mathrm{T}$ and B lymphomas. They are defined as a lymphocyte proliferation strictly localized on the skin without initial extra skin extension [3].

T cells cutaneous lymphomas term was used since 1979, to describe this heterogeneous group of $\mathrm{T}$ cells malignant lymphomas affecting mainly skin.

The incidence of these $T$ cells cutaneous lymphomas has not stopped increasing, probably because of the improvement of diagnostic means, the early detection and the environment factors in the genesis of this pathology [4].

Mycosis fungoides (MF) and its variants are the most frequent subgroup of T-cell cutaneous lymphomas [5], representing about 50\% of these lymphomas [6].

The etiopathogenesis of this lymphoma is still poorly understood [5] [7]. It carcinogenic process is probably multifactorial involving multiple risk factors genetic, infectious or environmental [8]. Few epidemiological studies have been led on these risk factors due to the rarity of this pathology. Indeed, the reported incidence rates of $\mathrm{T}$ cells cutaneous lymphomas, including MF are the most frequent subgroup, different between countries from 0.13 to $0.9 / 100,000$ people per year [9]. Until now, the only identified risk factors are male sex, advanced age and African-American race [4].

The occupational origin of this type of lymphoma was evoked by many authors. However, the results remain until today controversial [8] [10]. The professional factors complained of were solvents and pesticides but the reported results are often contradictory [8] [10]. Indeed, while some authors have found positive associations, others have not noticed any.

In this context, we carried out this case-control study dealing with all MF cases cared for in dermatology department of Farhat Hached teaching hospital of Sousse (Tunisia) during a period going from the beginning of 2003 to the end of 2015 whose goal was to determine the potential occupational factors correlated in the occurrence of MF.

\section{Methods}

It concerns a case-control survey carried out in dermatology department of Far- 
hat Hached teaching hospital of Sousse (Tunisia).The cases were all the patients suffering from MF followed-up in this department, over the period going from January 2003 to December 2015.

The diagnosis of the disease was suspected by a dermatologist and confirmed by anatomopathological examination.

Were excluded the patients not having exercised an occupational activity as well as those deceased before the survey and whose questionnaire couldn't be filled by relatives.

The witnesses were recruited randomly among patients consulting in the department of occupational medicine of Farhat Hached teaching hospital o Sousse, free from MF and any dermatological, cancerous and hematological pathology and were related to age, gender and geographical origin cases.

The number of collected MF cases during study period was 36 divided into 21 men and 15 women with a sex-ratio of 1.4.

Moreover, 4 files were abandoned because of the lack of information the lack of information of subjects contact details and 8 others were excluded, given that patients didn't exercise any occupational activity during their life.

In the end, only 24 files could be exploited. The MF carrier patients were divided in 17 men and 7 women with a sex-ratio of 2.4. The same number of cases was recruited for witnesses.

The collected information both for the case and witnesses focused on Sociodemographic characteristics (age, gender, origin, socio-economic level), lifestyle (smoking, alcoholism, leisure activity), medical data (personal and medical history, history of the disease, extent and appearance of the lesions, treatment and evolution) and occupational data (occupation, sector of activity, occupational exposure to pesticides, to organic solvents, to silica, to ionizing radiations, to anesthetic gas, to metals, to textile dust, to paintings ...).

All occupations and occupational exposure exceeding 6 months were identified both for the case and witnesses.

Data collection was done by a direct interview for interviews and by telephone interview for cases. For deceased patients, data were obtained by telephone interview with one of the patient relatives.

Medical files of cases and witnesses were consulted in order to complete missing medical data.

The whole survey was carried out by an occupational physician, after having obtained the oral consent of participants while respecting the anonymity and confidentiality of data.

The seizure and analysis of data were carried out thanks to SPSS software. In the descriptive study, we determined the frequencies and the percentage for qualitative variables and averages and standard variables for quantitative variables.

A bivariate analysis was carried out and we used the chi-squared test $\left(\chi^{2}\right)$ for the comparison of frequencies and the $t$ test of Student for the comparison of averages of two samples with a confidence interval at $95 \%$ and a significance level fixed at $5 \%$. 


\section{Résultats}

The average age of our cases was $55.41 \pm 17.4$ years versus $53.66 \pm 16.2$ years for witnesses.

Socio-medical characteristics as well as lifestyles of cases and witnesses are summarized in Table 1.

Table 1. Socio-medical characteristics and cases and witnesses lifestyle.

\begin{tabular}{|c|c|c|c|c|c|}
\hline Variables & Cases (\%) & Witnesses (\%) & $\mathrm{P}$ & OR & IC [95\%] \\
\hline \multicolumn{6}{|c|}{ Educational level: } \\
\hline Illiterate & 12.5 & 12.5 & 0.32 & & \\
\hline Primary & 83.3 & 70.8 & & & \\
\hline Others & 14.2 & 16.6 & & & \\
\hline \multicolumn{6}{|l|}{ Origin: } \\
\hline Rural & 83.3 & 70.8 & 0.59 & 0.48 & $0.12-1.9$ \\
\hline Urban & 16.7 & 29.2 & & & \\
\hline \multicolumn{6}{|c|}{ Socioeconomic level: } \\
\hline Low & 62.5 & 41.6 & & & \\
\hline Average & 37.5 & 58.4 & 0.14 & & \\
\hline High & 0 & 0 & & & \\
\hline \multicolumn{6}{|l|}{ Smoking: } \\
\hline Yes & 33.3 & 29.1 & 0.94 & 2.4 & $1.2-5.6$ \\
\hline No & 66.7 & 70.9 & & & \\
\hline \multicolumn{6}{|c|}{ Smoking $>40 \mathrm{PA}$} \\
\hline Yes & 45.8 & 20.8 & 0.027 & 6.6 & $1.22-35.4$ \\
\hline No & 54.2 & 79.2 & & & \\
\hline \multicolumn{6}{|l|}{ Alcoholism: } \\
\hline Yes & 25 & 12.5 & 0.46 & 2.3 & $1.2-10.6$ \\
\hline No & 75 & 87.5 & & & \\
\hline \multicolumn{6}{|c|}{ Practice a leisure activity: } \\
\hline Yes & 16.6 & 25 & 0.72 & 0.6 & $0.14-2.47$ \\
\hline No & 83.3 & 75 & & & \\
\hline \multicolumn{6}{|l|}{ Family history: } \\
\hline Atopy & 4.2 & 0 & 0.47 & & \\
\hline Myeloma & 4.2 & 0 & & & \\
\hline Others & 20.8 & 12.5 & & & \\
\hline \multicolumn{6}{|c|}{ Personal history: } \\
\hline Any & 37.5 & 50 & 0.57 & & \\
\hline Diabetes & 16.6 & 8.3 & & & \\
\hline Skin diseases & 8.2 & 20.8 & & & \\
\hline Others & 45.8 & 20.8 & & & \\
\hline
\end{tabular}


Smoking was reported by the cases and the witnesses in respectively $33.3 \%$ and $29.1 \%$ of cases without there being a statistically significant difference $(p=$ 0.94).

Among the smokers, a tobacco consumption higher than 40 Pack-year was noted in $45.8 \%$ of cases and in $20.8 \%$ of witnesses with a statistically significant difference $(p=0.027$ and an $\mathrm{OR}=6.6$; IC [1.22 - 35.4].

The set of chemical characteristics of cases is summarized in Table 2.

The average age of the beginning of MF was $52.6 \pm 17.5$ years with extremes ranging from 20 to 85 years and an average duration of evolution was $4.1 \pm 4.8$ years with extremes ranging from 1 month to 17 years.

The most found cutaneous lesions appearance was premycosis erythema (75\%), sitting mainly in lower members.

The evolution was favorable (recovery or stability) for most of our patients (70.8\%).

Three patients were deceased due to MF with an average survival time of 5 years.

Concerning occupational data, we noted that our cases had exercised mainly in the textile sector $29.1 \%$ versus $4.1 \%$ for witnesses.

MF risk of occurrence was higher in those who exercised in the textile sector with a statistically significant difference $(p=0.048)$; OR: 9.4; IC [1.06 - 84.3].

Most cases and witnesses were workers in $66,6 \%$ respectively without statistically significant difference.

Table 2. Chemical characteristics of cases.

\begin{tabular}{cc}
\hline Variables & Cases (\%) \\
\hline Aspect of lesions: & 75 \\
Premycosis erythema & 20.8 \\
Infiltrated plate & 4.1 \\
Tumors & 8.3 \\
Association & \\
Seat: & 75 \\
Lower limb & 58.3 \\
Upper limb & 66.6 \\
Torso & 4.1 \\
Neck & \\
Treatment: & 33.3 \\
Dermocorticoids & 37.5 \\
Methotrexate & 16.6 \\
Retinoids & 8.3 \\
PUVA Therapy & 16.6 \\
Any & \\
Evolution: & \\
Healing & 25 \\
Stability & 45.8 \\
Recurrence & 12.6 \\
Death &
\end{tabular}


Most of our cases (62.5\%) were exposed to products considered to be at risk versus $33.3 \%$ of witnesses with a statistically significant difference ( $p=0.043$ ).

MF risk of occurrence was higher in those exposed to products considered to be at risk with $\mathrm{OR}=3.33$; IC [1.02 - 10.89].

Among the products to which our patients were exposed, Diesel exhaust gas more represented in the cases, namely $29.1 \%$ versus $4.1 \%$ for witnesses with a statistically significant difference $(p=0,048)$.

MF risk of occurrence was higher in those exposed to this gas with an $\mathrm{OR}=$ 9.47; IC [1.06 - 84.3].

At the time of our investigation, $54.1 \%$ of our patients had resumed the same work station and $16.6 \%$ were applied to medical retirement.

Table 3 displays occupational factors of cases and witnesses.

\section{Discussion}

$\mathrm{MF}$ is the most frequent cutaneous $\mathrm{T}$ lymphoma, but whose etiology remains unknown. The role of occupational factors was reported by certain authors [10] [11].

In this context, this investigation was led whose objective was to search for different occupational risk factors involved in the genesis of this pathology in our establishment.

Our study recognizes certain limits which should be highlighted. It is about the selection bias since only the hospitalized patients in the dermatology department of Farhat Hached teaching hospital in Sousse (Tunisia) were included in the study.

We highlight in this context the lack of National Cancer registry in Tunisia making thus more difficult case recruitment. The second limit is the small size of our sample. Yet, let's recall that MF is a rare disease and our study focused on a period of 13 years. Likewise, the retrospective nature of our survey leads to the difficulty in establishing definite causality links between the involved factor and the risk of MF occurrence. Finally, broad OR were found most likely secondary to a power problem and low workforce in certain categories, nevertheless, these intervals were significant. Yet, our study presents some strengths which should be underlined. Indeed, the authors only included patients whose diagnosis was histologically confirmed; exposure was evaluated in the same way for cases and witnesses taking into account, not only of current exposures, but also past ones and the authors had also taken into account both occupational and extraprofessional factors in order to limit the effect of distorter variables.

At the term of our enquiry, tobacco consumption higher than 40 PA, exercise in the textile sector and exposure to some Diesel type solvents were significantly associated with the MF occurrence risk.

The role of tobacco in the genesis of MF is still controversial in the literature. While in a multicentric study, led in six European countries, authors concluded to a significant link [9]. In the studies of Morton LM and al. [12] and Tuyp E et al. [13], smoking had not been retained among MF risk factors. 
Table 3. Studied occupational factors.

\begin{tabular}{|c|c|c|c|c|c|c|}
\hline Variables & Co variables & Cases & Witnesses & $\mathrm{P}$ & OR & IC \\
\hline \multirow{12}{*}{ Business sector } & Textile & & & & & \\
\hline & Yes & $29.1 \%$ & $4.1 \%$ & 0.048 & 9.4 & $1.06-84.3$ \\
\hline & No & $70.9 \%$ & $95.9 \%$ & & & \\
\hline & Agriculture & & & & & \\
\hline & Yes & $25 \%$ & $25 \%$ & 1 & 1.2 & $0.32-4.8$ \\
\hline & No & $75 \%$ & $75 \%$ & & & \\
\hline & Hotel and catering sector & & & & & \\
\hline & Yes & $8.3 \%$ & $0 \%$ & 0.23 & 1.09 & $0.9-1.2$ \\
\hline & No & $91.7 \%$ & $100 \%$ & & & \\
\hline & Painting & & & & & \\
\hline & Yes & $8.3 \%$ & $0 \%$ & 0.23 & 1.09 & $0.9-1.2$ \\
\hline & No & $91.7 \%$ & $100 \%$ & & & \\
\hline \multirow[t]{9}{*}{ Seniority } & & $\begin{array}{c}28.1 \pm 9.44 \\
\text { ans }\end{array}$ & $\begin{array}{l}24.29 \pm \\
16.5 \text { ans }\end{array}$ & 0.37 & & \\
\hline & Risk products & & & & & \\
\hline & Yes & $62.5 \%$ & $33.3 \%$ & 0.0043 & 3.33 & $1.02-10.89$ \\
\hline & Non & $37.5 \%$ & $66.6 \%$ & & & \\
\hline & Diesel exhaust gas & & & & & \\
\hline & Yes & $29.1 \%$ & $4.1 \%$ & 0.05 & 9.47 & $1.06-84.37$ \\
\hline & No & $70.9 \%$ & $95.9 \%$ & & & \\
\hline & Solvents & & & & & \\
\hline & Yes & $12.5 \%$ & $12.5 \%$ & 1 & 1 & $0.1-5.5$ \\
\hline \multirow{12}{*}{$\begin{array}{l}\text { Products } \\
\text { involved }\end{array}$} & Non & $87.5 \%$ & $87.5 \%$ & & & \\
\hline & Pesticides & & & & & \\
\hline & Oui & $25 \%$ & $16.6 \%$ & 0.72 & 1.6 & $0.4-6.8$ \\
\hline & No & $75 \%$ & $83.4 \%$ & & & \\
\hline & Painting & & & & & \\
\hline & Yes & $8.3 \%$ & $0 \%$ & 0.24 & 1.5 & $0.04-6.9$ \\
\hline & No & $91.7 \%$ & $100 \%$ & & & \\
\hline & Textile dust & & & & & \\
\hline & Yes & $20.8 \%$ & $4.1 \%$ & 0.2 & 2.8 & $0.5-16.6$ \\
\hline & No & $79.2 \%$ & $95.9 \%$ & & & \\
\hline & Protection means: & & & & & \\
\hline & Yes & $4.2 \%$ & $8.4 \%$ & 0.7 & 0.47 & $0.04-5.6$ \\
\hline \multirow{4}{*}{$\begin{array}{c}\text { Exposure } \\
\text { characteristics }\end{array}$} & No & $95.8 \%$ & $91.6 \%$ & & & \\
\hline & Periodic monitoring: & & & & & \\
\hline & Yes & $25 \%$ & $12.5 \%$ & 0.2 & 0.3 & $0.12-9.3$ \\
\hline & No & $75 \%$ & $87.5 \%$ & & & \\
\hline
\end{tabular}


In our study, tobacco consumption higher than 40 Pack-year was significantly associated with MF occurrence risk with an OR = 6.6; IC [1.22 - 35.4].

Chronic exposure to cigarette smoke is associated with decreased immune reactivity, especially, of $\mathrm{T}$ cells, which suggests a potential link between impaired immune function and increased risk of lymphoma [11].

Drinking had also been incriminated according to some authors in the increased risk of MF in case of a daily drinking; however, no mechanism was demonstrated or suspected up to the present day [9].

Furthermore, it's reported in the literature that a moderate physical activity can improve the immune function and then protect against NHL and possibly MF [14] [15]. In the study of Briesi et al. [11], MF risk reduction was noted in the group of people engaged in a leisure activity compared to others.

Among incriminated family history in MF occurrence, according to the literature, we notice atopy and myeloma [11] [13] [15]. However, so far the results are not yet conclusive [16].

Indeed, in the studies of Tuyp E and al [13] and Morales MM et al. [15], a significant association between MF and atopic manifestations (atopic dermatitis, asthma, urticaria) was detected. Yet, other studies [16], didn't reveal any significant difference between prevalence of atopy in patients suffering from MF and that in overall population.

On the other hand, Briseis A et al. [11], had reported that subjects with myeloma family history would have an acute MF risk.

Concerning personal medical history, dermatitis (known as eczema) is an MF risk factor. Indeed, it is about a form of chronic dermatitis known for having a pathogenic association with MF first stages [17]. What allows explaining the fact that, in some cases, MF at the beginning stage can be confused with Eczema [11].

The possibility of a causal relationship between occupational factors and MF attracted a lot of interest of a good number of researchers.

In our study, the risk of MF was higher significantly in the sector of textile activity.

This result was consistent with some authors who showed that this sector is a high risk sector [11] [13] [18] [19].

In the literature, the different sectors described as being high risk sectors different from one study to another.

This concerns, in particular, agriculture, painting, carpentry, petrochemistry, metallurgy and hotel trade and catering [9] [11] [18] [20]. Solvents are products broadly used in many activity sectors [21].

The causality relationship between MF and solvent exposure was suggested by few studies. In the study of Morales-Suarez-Varela MM and al published in 2013 [8], the authors didn't find any significant difference between cases and witnesses in men.

However, in women, a significant association was observed with exposure at a very high level of perchlorethylene (OR = 11.38; IC at 95\% [1.04 - 124.85]) and 
exposure at a level lower than the median of gas-oil/kerosene/fuel $(\mathrm{OR}=8.53$; IC at $95 \%$ [1.11 - 65.62]). This notification was not objectified by our study.

In the literature, there is a controversy on pesticide exposure and MF occurrence [22]. According to Morales MM et al. [10], prolonged exposure to pesticides ( $>10$ years) is associated with a high risk of MF. In our study, there was not an association between a pesticide exposure and risk of MF occurrence.

Diesel exhaust particles are the main substances involved in ambient air pollution with widely considered adverse health effects [23]. However, there is little data available on the impact of diesel exhaust on lymphocyte function. In our study, the risk of occurrence of MF was higher in exposed diesel exhaust gases with an OR = 9.47; IC [1.06 - 84.3]. However, no study in the literature has reported a probable relationship between this exposure and the risk of FM occurrence.

According to Pierdominici and al [23], exposure to these gases causes a blocking marked by lysomal autophalgy interfering in this way with T-cell lymphoma homeostasis. This could harmful, at least in the long term, by favoring the development or the progression of certain diseases such as autoimmune diseases and neoplasia. This neoplasic risk attributed to Diesel smoke exposure was essentially reported for NHL [24] [25].

Moreover, many other toxic substances (such as silica, ionizing radiation, anesthetic gas, metals, textile dust, paintings) were studied in order to prove their role in the genesis of MF [10] [13] [26] [27] [28]. Nevertheless, the results remain inconclusive and contradictory.

\section{Conclusions}

T-cell lymphomas are the most frequent cutaneous lymphomas and Mycosis Fungoides the most frequent of cutaneous T-cell lymphomas. Its etiology remains nonetheless unknown.

MF increased incidence suggests that environmental, of chemical or immune nature factors could play an important role in the genesis of this pathology.

In terms of our study, the factors that were associated, in a significant way, with the risk of MF occurrence were tobacco consumption, exercise in the textile sector and exposure to Diesel exhaust gas. The adequate prevention should be thus underlined, involving the fight against smoking on the one hand, and the strengthening of the primary prevention namely in risk sectors on the other hand. Multicentric investigations were necessary in order to elucidate the probable role of occupational factors in the genesis of this pathology.

\section{Conflicts of interest}

The authors state not to have conflicts of interest in relation to this article.

\section{Data Availability}

The readers can access the data supporting the conclusions of the study by 
sending a mail to the corresponding author.

\section{References}

[1] Dilhuydy, J.M., Guillemart, M.H., Dilhuydy, M.H., Dohollou, N. and Les, R.J. (1991) cancers professionnels: Identification, prévention et réparation. Concours $M e, 38,3419-3426$.

[2] El Maalel, O., Boughattas, W., Maoua, M., Kalboussi, H., Bougmiza, I., Rhif, H., Chatti, S., N'Daye, K., Debbabi, F., Mitraoui, A. and Mrizak, N. (2012) Extraprofessionnel and Occupational Risk Factors for Colorectal Cancer. J. Life Sci, 6, 848-857.

[3] Kim, Y.H., Willemze, R., Pimpinelli, N., et al. (2007) TNM Classification System for Primary Cutaneous Lymphomas Other than Mycosis Fungoides and Sezary Syndrome: A Proposal of the International Society for Cutaneous Lymphomas (ISCL) and the Cutaneous Lymphoma Task Force of the European Organization of Research and Treatment of Cancer (EORTC). Blood, 110, 479-484.

https://doi.org/10.1182/blood-2006-10-054601

[4] Criscione, V.D. and Weinstock, M.A. (2007) Incidence of Cutaneous T-Cell Lymphoma in the United States, 1973-2002. Arch Dermatol, 143, 854-859. https://doi.org/10.1001/archderm.143.7.854

[5] Zinzani, P.L., Ferreri, A.J.M. and Cerroni, L. (2008) Mycosis Fungoides. Critical Reviews in Oncology/ Hematology, 65, 172-182. https://doi.org/10.1016/j.critrevonc.2007.08.004

[6] Willemze, R., Jaffe, E.S., Burg, G., et al. (2005) WHO-EORTC Classification for Cutaneous Lymphomas. Blood, 105, 3768-3785.

https://doi.org/10.1182/blood-2004-09-3502

[7] Kin, E.J., Hess, S., Richardson, S.K., Newton, S., et al. (2005) Immunopathogenesis and Therapy of Cutaneous T Cell Lymphoma. Journal of Clinical Investigation, 115, 798-812. https://doi.org/10.1172/JCI24826

[8] Morales-Suarez-Varela, M.M., Olsen, J., Villeneuve, S., et al. (2013) Occupational Exposure to Chlorinated and Petroleum Solvents and Mycosis Fungoides. Journal of Occupational and Environmental Medicine, 55, 924-931. https://doi.org/10.1097/JOM.0b013e3182941a1c

[9] Suarez, M.M.M., Olsen, J., Kaerlev, L., et al. (2001) Are Alcohol Intake and Smoking Associated with Mycosis Fungoides? A European Multicentre Case-Control Study. European Journal of Cancer, 37, 392-397. https://doi.org/10.1016/S0959-8049(00)00383-X

[10] Morales-Suarez-Varela, M.M., Olsen, J., Johansen, P., et al. (2005) Occupational Exposures and Mycosis Fungoides. A European Multicentre Case-Control Study (Europe). Cancer Causes Control, 16, 1253-12539. https://doi.org/10.1007/s10552-005-0456-6

[11] Aschebrook-Kilfoy, B., Cocco, P., La Vecchia, C., Chang, E.T., et al. (2014) Medical History, Lifestyle, Family History, and Occupational Risk Factors for Mycosis Fungoides and Sézary Syndrome: The InterLymph Non-Hodgkin Lymphoma Subtypes Project. JNCI Monographs, 48, 98-105. https://doi.org/10.1093/jncimonographs/lgu008

[12] Morton, L.M., Hartge, P., Holford, T.R., et al. (2005) Cigarette Smoking and Risk of Non-Hodgkin Lymphoma: A Pooled Analysis from the International Lymphoma Epidemiology Consortium (InterLymph). Cancer Epidemiology, Biomarkers \& Prevention, 14, 925-933. https://doi.org/10.1158/1055-9965.EPI-04-0693 
[13] Tuyp, E., Buroyne, A., Aitchinson, T. and Mackie, R. (1987) A Case-Control Study of Possible Causative Factors in Mycosis Fungoides. Arch Dermatol, 123, 196-200. https://doi.org/10.1001/archderm.1987.01660260066015

[14] Cerhan, J.R., Bernstein, L., Severson, R.K., et al. (2005) Anthropometrics, Physical Activity, Related Medical Conditions, and the Risk of Non-Hodgkin Lymphoma. Cancer Causes Control, 16, 1203-1214. https://doi.org/10.1007/s10552-005-0358-7

[15] Morales, M.M., Oslen, J., Johansen, P., Kaerlev, L., Guénel, P., Arveux, P., et al. (2003) Viral Infection, Atopy and Mycosis Fungoides: A European Multicentre Case-Control Study. European Journal of Cancer, 39, 511-516. https://doi.org/10.1016/S0959-8049(02)00773-6

[16] Mehrany, K., Elazhary, R.A., Bouhuis, S.A. and Pittelkow, M.R. (2003) Epidemiology and Health Services Research. Cutaneous T-Cell Lymphoma and Atopy: Is There an Association? British Journal of Dermatology, 149, 1013-1017. https://doi.org/10.1111/j.1365-2133.2003.05551.x

[17] Burg, G., Dummer, R., Haeffner, A., Kempf, W. and Kadin, M. (2001) From Inflammation to Neoplasia: Mycosis Fungoides Evolves from Reactive Inflammatory Conditions (Lymphoid Infiltrates) Transforming into Neoplastic Plaques and $\mathrm{Tu}$ mors. Archives of Dermatology, 137, 949-952.

[18] Linet, M.S., McLaughlin, J.K., Malker, H.S., et al. (1994) Occupation and Hematopoietic and Lymphoproliferative Malignancies among Women: A Linked Registry Study. Journal of Occupational and Environmental Medicine, 36, 1187-1198. https://doi.org/10.1097/00043764-199411000-00004

[19] Kuzel, T.M., Roenigk, H.H. and Rosen, S.T. (1991) Mycosis Fungoides and the Sezary Syndrome: A Review of Pathogenesis, Diagnosis, and Therapy. Journal of Clinical Oncology, 9, 1298-1313. https://doi.org/10.1200/JCO.1991.9.7.1298

[20] Morales, M., Olsen, J., Johansen, P., et al. (2004) Occupational Risk Factors for Mycosis Fungoides: A European Multicenter Case-Control Study. Journal of Occupational and Environmental Medicine, 46, 205-211. https://doi.org/10.1097/01.jom.0000116819.01813.8c

[21] Lauwreys, R. (1982) Toxicologie industrielle et intoxications professionnelles. 2nd Edition, Masson, Amsterdam.

[22] Testud, F. (2001) Pathologie toxique en milieu du travail., 2nd Edition revue et augmentée, Editeur ESKa.

[23] Pierdominici, M., Maselli, A., Cecchetti, C., Tinari, A., Mastrofrancesco, A., Alfè, M., et al. (2014) Diesel Exhaust Particle Exposure in Vitro Impacts T Lymphocyte Phenotype and Function. Particle and Fibre Toxicology, 11, 74. https://doi.org/10.1186/s12989-014-0074-0

[24] Karunanayake, C., McDuffie, H., Dosman, J., Spinelli, J. and Pahwa, P. (2008) Occupational Exposures and Non-Hodgkin's Lymphoma: Canadian Case-Control Study. Environmental Health, 7, 44. https://doi.org/10.1186/1476-069X-7-44

[25] Baris, D., Garrity, T.J., Telles, J.L., Heineman, E.F., Olshan, A. and Zahm, S.H. (2001) Cohort Mortality Study of Philadelphia Firefighters. American Journal of Industrial Medicine, 39, 463-476. https://doi.org/10.1002/ajim.1040

[26] Fischmann, A.B., Bunn, P.A., Guccion, J.G., Mathews, M.J. and Minna, J.D. (1979) Exposure to Chemical, Physical Agents and Biological Agents in Mycosis Fongoides and Sezary Syndrome. Cancer Treatment Reports, 63, 591-596.

[27] Whittemore, A.S. and Holly, E.A. (1989) Mycosis Fungoides in Relation to Environmental Exposures and Immune Response: A Case-Control Study. Journal of the 
National Cancer Institute, 81, 1560-1567.

https://doi.org/10.1093/jnci/81.20.1560

[28] Nikkels, A.F., Quatresooz, P., Delvenne, P., Balsat, A. and Pierzrd, G.E. (2004) Mycosis Fungoides Progression and Chronic Solvent Exposure. Dermatology, 208, 171-173. https://doi.org/10.1159/000076496 